\title{
Application of policy analysis frameworks in tobacco control research: A systematic review of qualitative literature
}

\author{
Jalal Arabloo ${ }^{1}$, Sogand Tourani², Hamid Ravaghi*2 \\ Received: 23 Sep 2017 \\ Published: 25 June 2018
}

\begin{abstract}
Background: Tobacco consumption is still considered as the first preventable cause of death in the world. In order to influence tobacco policy process, researchers and policymakers must use frameworks of policy-making to understand the process to provide them insights for influence the process. This systematic review aims to review the application of policy analysis frameworks in the field of tobacco control.

Methods: A systematic search for articles was performed using four databases (Ovid Medline, Scopus, Cochrane Library, and PubMed) up to December 19, 2016. The articles were selected based on inclusion and exclusion criteria. All research studies focusing on tobacco policy and on one or more specified frameworks of policy analysis included in this study. Finally, thematic analysis was used to synthesize the findings.

Results: 17 studies based on eligibility criteria were included in this study. The findings of this study showed that most of the studies were in North America, published in the Health journals, conducted to analyze the national and state policies, focused on analyzing agenda-setting phase. Multiple streams model was the most widely used framework within the literature. Few studies had used advocacy coalition framework. From the three agenda setting frameworks and theories (MSF, PEF, ACF), the ACF framework is the most detailed framework in terms of elements and factors affecting the dynamics of political sub-system the reasons for models selection and suitability for the study was noted only in a small number of studies. The results of this study showed underuse and the incomplete or improper use of policy analysis models and frameworks in the field of tobacco research.

Conclusion: The study showed that a number of theories and frameworks have been used but their use was limited and have significant methodological weaknesses.
\end{abstract}

Keywords: Tobacco, Systematic review, Policy analysis

Copyright $\subseteq$ Iran University of Medical Sciences

Cite this article as: Arabloo J, Tourani S, Ravaghi H. Application of policy analysis frameworks in tobacco control research: A systematic review of qualitative literature. Med J Islam Repub Iran. 2018 (25 June);32:52. https://doi.org/10.14196/mjiri.32.52

\section{Introduction}

Tobacco epidemic is one of the leading public health threats the world has ever faced. Tobacco consumption is still considered as the first preventable cause of death in the world (1). Despite progress in tobacco control policies, global tobacco epidemic still continues to grow exponentially in the twentieth century. In response to this epidemic, the World Health Organization codified the first public health treaty, i.e. the Framework Convention on Tobacco Control in 2003 (2).

Tobacco control is difficult due to powerful economic and political forces that are created by the production and sale of Tobacco products. In other words, through transna-

Corresponding author: Dr Hamid Ravaghi, ravaghi.h@iums.ac.ir

1. Department of Health Management and Economics, School of Public Health, Tehran University of Medical Sciences, Tehran, Iran

2. Department of Health Services Management, School of Health Management and Information Sciences, Iran University of Medical Sciences, Tehran, Iran. tional actors, uneven distribution of costs and benefits of the tobacco industry, the extent of the economic benefits and costs of tobacco health and diversity of actors having interests in the tobacco trade, its control is complex and difficult. In many low- and middle-income countries, slow progress towards the complete tobacco control in some areas and complete failure in other areas, testify to the power of these forces. Paying attention to the economic and political dimensions of this issue, could help the development of strategies to help the adoption and implementation of policies (3). Therefore, while there is enough scientific evidence about the spread of tobacco and its

$\uparrow$ What is "already known" in this topic:

So far, no review study investigating the use of theories and policy process frameworks in the field of tobacco control studies has been carried out

$\rightarrow$ What this article adds:

The results of this study showed underuse and the incomplete or improper use of policy analysis models and frameworks in the field of tobacco research. 
widespread economic and social effects, insufficient perception of the policy environments in which effective forces interact tobacco control policies, and in it tobacco control policies are codified and implemented, could be seen. This is outstanding especially in low- and middleincome countries, however, it is expected that global tobacco epidemic influence these countries as bad as it could and face tobacco control policies with greatest political challenges (4). Also, policy studies conducted in order to find the views of stakeholders in all the fields of tobacco control policies in Thailand and Zimbabwe showed that an immediate need to develop the number of policy studies in low- and middle-income countries could be felt (5). Since in order to optimally affect general policies that are effective on tobacco control, a full perception of policy processes seems necessary. For this purpose, the frameworks, theories, and models of policy analysis are used. If researches achieve more perception of the policy process and the value of using policy analysis theories in their studies, they would be able to be more effective in entering issues by order of governmental policies (6). Studies have also shown that inadequate understanding of the environment of politics and policy lead to the fact that political entrepreneurs cannot exploit windows of opportunity in making political changes (7).

About the use of policy analysis models in public health, several systematic reviews have been carried out $(6,8-12)$. But so far a review study that investigates the use of theories and policy process frameworks in the field of tobacco control studies, is not carried out. This systematic review aims to review the application of policy analysis frameworks in the field of tobacco control.

\section{Methods}

At this stage, with the use of different literature search methods such as electronic sources searching through keywords and codifying search strategy was carried out to identify studies in the field of tobacco that used selective conceptual frameworks of policy analysis. First, an initial search was performed to identify relevant literature so as to complete research keywords.

\section{Identification of studies}

Searching electronic databases: In the present systematic review, systematic search of studies with the use of the following databases was performed until 19 December 2016: Ovid MEDLINE(R), SCOPUS, Cochrane library, PubMed. Search strategy contains a combination of keywords and mesh. Search strategies are shown in Appendixes 1, 2, 3, and 4. There was no restriction on language or publication date.

Searching other sources: To search in gray literature Google Scholar was used. List of included study references was further screened in order to find eligible studies. Efforts were made to contact experts and key informers who are active in the field of tobacco policy analysis if necessary.

\section{Eligibility criteria}

\section{Inclusion criteria}

- The focus is on one or more frameworks of policy analysis. In the present study, the purpose of conceptual frameworks were the common policy analysis frameworks which are chosen based on the works of Sabatier (13) and other sources (14), include: multiple streams framework, advocacy coalition framework, punctuated equilibrium framework, policy analysis triangle framework, stages heuristic, and institutional analysis and development framework (Table 1).

- Focus on tobacco policy

- It is a research paper.

Exclusion criteria

- Non-English articles.

- Studies not published as a peer-reviewed article

\section{Selection of studies}

After removing duplicate articles, initially, titles and abstracts of articles were screened by one of the researchers, and only those articles with at least one of the inclusion criteria were selected for screening in the second phase. At the second phase, full-text of included articles from the first phase were examined separately by two researchers in terms of eligibility criteria. Differences were solved

Table 1. Policy analysis frameworks included in the study

\section{Theory of the policy process \\ Multiple Streams Framework}

Advocacy Coalition Framework

Punctuated Equilibrium Framework

Institutional Analysis And Development Framework

Policy Analysis Triangle Framework

Stage Heuristic Framework

\section{Description}

This framework proposes that policy formation is the consequence of three sets of processes: problems, policies and politics. The problem stream, relates to issues that require action. The policy stream focuses on the solutions available to address identified problems. The politics stream refers to the broader political discourse. This is influenced by national mood, pressure group advocacy, and administrative or legislative turnover. Changes in the politics stream are seen as the most powerful for reshaping the policy agenda. This framework posits that policy choices are made when the three streams are coupled or joined together at critical moments in time and these are referred to as 'windows of opportunity'.

The framework focuses on the interaction within a policy subsystem of a small number of advocacy coalitions comprised of actors from a variety of institutions sharing a set of policy beliefs.

This framework argues that policymaking is characterized by long periods of incremental change punctuated by brief periods of major policy change

The IAD deliberates how individual policy actors make decisions within institutions which affect human behaviour. The focus unit of analysis for the IAD is the "action situation" which is determined by the analyst, as per the context

Walt and Gilson (1994) developed this framework specifically for health. This framework focuses on actors, context and the content and processes of policies.

The most famous public policy framework is the stages heuristic It divides the public Policy process into a series of stages: agenda setting, formulation, implementation, and evaluation. 
through an agreement between the researchers and in case of disagreement through discussion with a third researcher. The agreement was reached on all included studies.

\section{Data extraction}

Data related to the full-text of included articles were extracted by one of the researchers with the use of a standard extraction form, and were controlled and investigated in terms of correctness by another researcher.

\section{Quality appraisal of articles}

Considering that the aim of this study is to understand the application of frameworks of policy, hence in the present study all the included studies were used, but in the final analysis and conclusion, the emphasis was on highquality articles. Checklist of Critical Appraisal Skills Program (CASP) was used to evaluate the quality of articles.

\section{Data synthesis}

After collecting data from the included articles, thematic analyses (qualitative synthesis) were used to describe characteristics of included studies. The themes of the present study were the frameworks used, and the findings were grouped according to these frameworks. This systematic review has been reported based on PRISMA guide (16).

\section{Results}

\section{Quantity and quality of evidence}

The present systematic review, was conducted in December 2016. Four databases led to a total of 354 articles by selected keywords. 277 articles remained after the removal of duplicate articles. Titles and abstracts of these articles were screened, and 20 articles remained. Full text of articles obtained from the previous stage were examined based on inclusion and exclusion criteria determined by the investigators. Three articles were omitted because of not using determined policy analysis frameworks. Finally, based on compliance with these criteria, 17 articles were included in the final stage. (Fig. 1; Table 2).
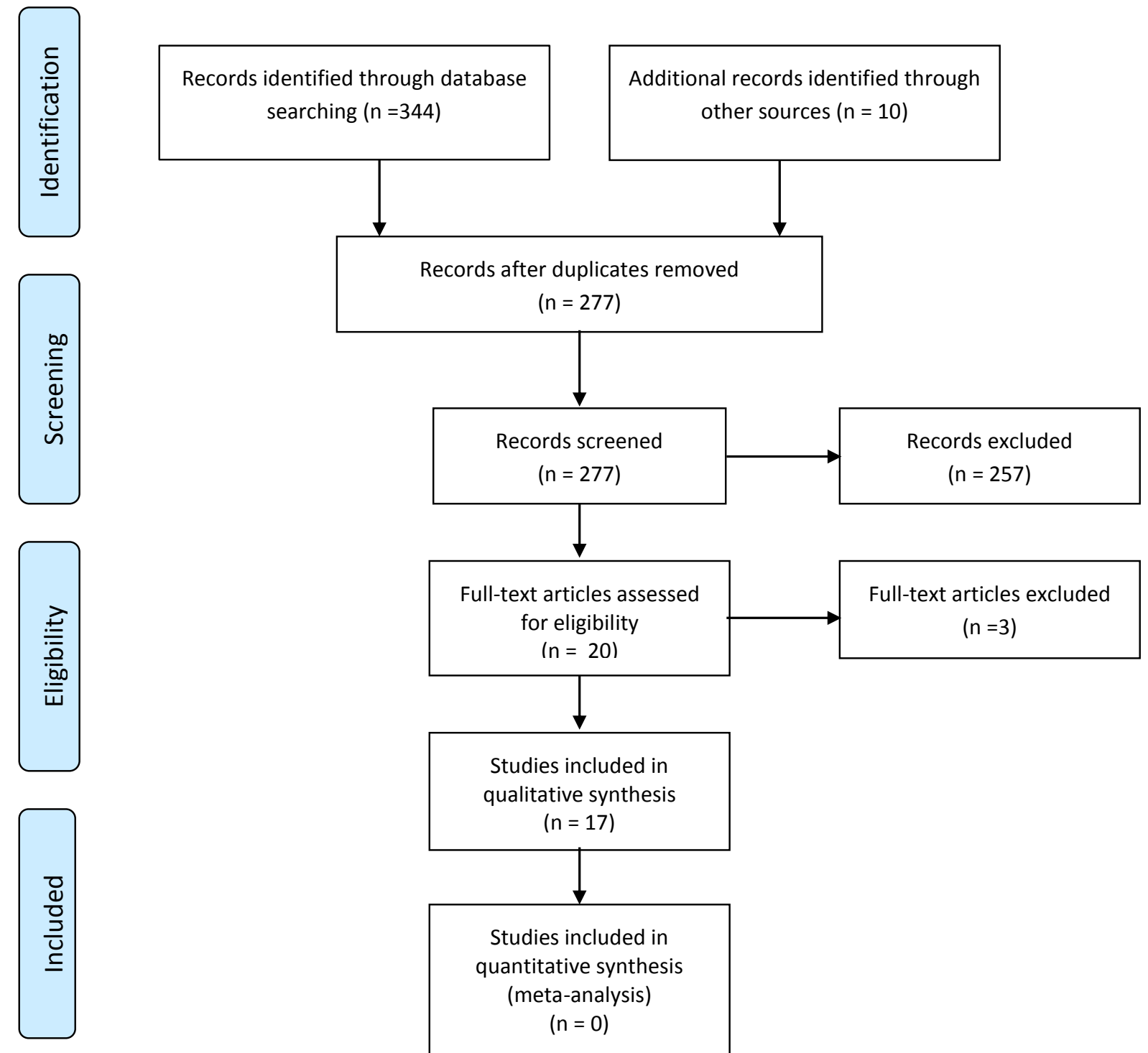

Fig. 1. Literature search flow diagram 


\begin{tabular}{|c|c|c|c|c|c|c|c|}
\hline $\begin{array}{l}\text { Model } \\
\text { use }\end{array}$ & $\begin{array}{l}\text { Author } \\
\text { (Year) }\end{array}$ & $\begin{array}{l}\text { Research } \\
\text { setting }\end{array}$ & $\begin{array}{l}\text { Journal } \\
\text { Area }\end{array}$ & Analysis Level & $\begin{array}{l}\text { policy-making } \\
\text { Stage }\end{array}$ & Method & Issue \\
\hline PTF & $\begin{array}{l}\text { Currie \& } \\
\text { Clancy } \\
(2010)\end{array}$ & Ireland & Health & National & all stages & $\begin{array}{l}\text { document analysis, } \\
\text { interviews with key } \\
\text { informants }\end{array}$ & $\begin{array}{l}\text { tobacco-free policy-making } \\
\text { process in Ireland }\end{array}$ \\
\hline PTF & $\begin{array}{l}\text { Lunze\& } \\
\text { Migliorini } \\
\text { (2013) }\end{array}$ & Russia & Health & National & all stages & Secondary data & $\begin{array}{c}\text { The analysis of past trends } \\
\text { and current tobacco epidem- } \\
\text { ic and tobacco control policy } \\
\text { responses in the Russian } \\
\text { Federation }\end{array}$ \\
\hline IADF & $\begin{array}{l}\text { Fallin et al } \\
\text { (2014) }\end{array}$ & USA & Health & Local/City & Implementation & $\begin{array}{c}\text { The mixed method } \\
\text { case study using } \\
\text { observation, inter- } \\
\text { views and secondary } \\
\text { data }\end{array}$ & $\begin{array}{l}\text { Implementation of smoke- } \\
\text { free policy } \\
\text { In three communities in the } \\
\text { state of Kentucky }\end{array}$ \\
\hline IADF & $\begin{array}{l}\text { Martinez } \\
(r \cdot . q)\end{array}$ & Spain & Health & Organizational & Implementation & Unclear & $\begin{array}{l}\text { Implementation of tobacco } \\
\text { control policies in hospitals } \\
\text { in Catalan }\end{array}$ \\
\hline MST & $\begin{array}{l}\text { Greathouse } \\
\text { et al. (2005) }\end{array}$ & USA & Health & State & $\begin{array}{l}\text { agenda Setting } \\
\text { and formulation }\end{array}$ & Unclear & $\begin{array}{l}\text { Smoke-free legislation in the } \\
\text { state of Kentucky }\end{array}$ \\
\hline MST & $\begin{array}{l}\text { Mamudu et } \\
\text { al. (2014) }\end{array}$ & USA & Health & State & $\begin{array}{l}\text { agenda Setting } \\
\text { and formulation }\end{array}$ & $\begin{array}{l}\text { case study using } \\
\text { interviews and doc- } \\
\text { ument analysis }\end{array}$ & $\begin{array}{l}\text { approval of non-smokers } \\
\text { protection law In Tennessee }\end{array}$ \\
\hline MST & $\begin{array}{l}\text { Schwartza\& } \\
\text { Johnson } \\
\text { (2010) }\end{array}$ & Canada & Health & National & agenda Setting & $\begin{array}{c}\text { Interviews, expert } \\
\text { panel and document } \\
\text { analysis }\end{array}$ & $\begin{array}{l}\text { Smuggling of tobacco prod- } \\
\text { ucts in Canada }\end{array}$ \\
\hline MST & $\begin{array}{l}\text { Blackman } \\
(2005)\end{array}$ & USA & Health & State & agenda Setting & Unclear & $\begin{array}{l}\text { provide a better understand- } \\
\text { ing of the policy making } \\
\text { process for nurses, with } \\
\text { examples of tobacco control } \\
\text { in California }\end{array}$ \\
\hline MST & $\begin{array}{l}\text { Hoe et al } \\
\text { (2016) }\end{array}$ & Turkey & Health & National & agenda Setting & $\begin{array}{l}\text { Case study using in- } \\
\text { depth interviews, } \\
\text { review of documents } \\
\text { and survey }\end{array}$ & $\begin{array}{l}\text { Process and determinants of } \\
\text { how tobacco control in } \\
\text { Turkey during the period } 30 \\
\text { year-old has become a polit- } \\
\text { ical priority }\end{array}$ \\
\hline MST & $\begin{array}{l}\text { Kehler } \\
\& \text { Hahn } \\
(2016)\end{array}$ & USA & Health & State & agenda Setting & Interviews & $\begin{array}{l}\text { Failure to comprehensive } \\
\text { smoke-free legislation in the } \\
\text { state of Kentucky, USA }\end{array}$ \\
\hline $\mathrm{ACF}$ & $\begin{array}{l}\text { Sato } \\
(1999)\end{array}$ & Japan & $\begin{array}{l}\text { Political } \\
\text { sciences }\end{array}$ & National & $\begin{array}{l}\text { agenda Setting } \\
\text { and formulation }\end{array}$ & Unclear & $\begin{array}{l}\text { tobacco control policymak- } \\
\text { ing process in Japan }\end{array}$ \\
\hline ACF & $\begin{array}{l}\text { Breton et al } \\
\quad(2006)\end{array}$ & Canada & Health & National & $\begin{array}{l}\text { agenda Setting } \\
\text { and formulation }\end{array}$ & $\begin{array}{l}\text { Case study using } \\
\text { multiple data } \\
\text { sources }\end{array}$ & $\begin{array}{l}\text { The struggle for reduce } \\
\text { tobacco products taxation to } \\
\text { control tobacco Smuggling }\end{array}$ \\
\hline ACF & $\begin{array}{l}\text { Breton et al } \\
\quad(2008)\end{array}$ & Canada & Health & State & $\begin{array}{l}\text { agenda Setting } \\
\text { and formulation }\end{array}$ & $\begin{array}{l}\text { Interviews and doc- } \\
\text { ument analysis }\end{array}$ & $\begin{array}{l}\text { tobacco control policy in } \\
\text { Quebec, Canada }\end{array}$ \\
\hline PET & $\begin{array}{l}\text { Givel } \\
\text { (2008) }\end{array}$ & USA & $\begin{array}{l}\text { Political } \\
\text { sciences }\end{array}$ & National & agenda Setting & Secondary data & $\begin{array}{l}\text { tobacco policy making in the } \\
\text { US }\end{array}$ \\
\hline PET & $\begin{array}{l}\text { Givel } \\
(2012)\end{array}$ & Bhutan & $\begin{array}{l}\text { Political } \\
\text { sciences }\end{array}$ & National & agenda Setting & $\begin{array}{l}\text { Interviews and doc- } \\
\text { ument analysis }\end{array}$ & $\begin{array}{c}\text { Anti-tobacco legislation in } \\
2004 \text { in Bhutan }\end{array}$ \\
\hline PET & $\begin{array}{l}\text { Givel } \\
(2006)\end{array}$ & USA & $\begin{array}{l}\text { Political } \\
\text { sciences }\end{array}$ & State & agenda Setting & Unclear & $\begin{array}{c}\text { State tobacco policies in the } \\
\text { US }\end{array}$ \\
\hline $\begin{array}{l}\text { PET, } \\
\text { ACF, } \\
\text { MST }\end{array}$ & $\begin{array}{l}\text { Cairney } \\
(2007)\end{array}$ & England & $\begin{array}{l}\text { Political } \\
\text { sciences }\end{array}$ & National & agenda Setting & Unclear & $\begin{array}{l}\text { Study of a period of rapid } \\
\text { change after decades of } \\
\text { stability in the tobacco prod- } \\
\text { ucts policy in Great Britain }\end{array}$ \\
\hline
\end{tabular}

Most of the included studies were published since 2000 onwards (7, 17-31). Only one study was done before 2000 (32). Studies included from America (7, 20, 22, 24-26, 31), Canada (17, 29, 30), Ireland (27), Spain (18), England (28), Russia (19), Turkey (21), Japan (32), and Bhutan (23). Twelve included articles were published in journals of health and medical (7, 17-22, 26, 27, 29-31). Other studies were published in the journals of political sciences $(23-25,28,32)$. On the basis of analysis level of policy, 9 studies had been conducted at national level $(17,19,21$, $23,24,27,28,30,32)$, six studies at state level $(7,20,22$, $25,29,31)$, one study at local level (26), and a study at organizational level (18). In terms of focus on steps of policies, two studies dealt with the analysis of the whole process of policies $(19,27)$, two studies dealt with implementation analysis $(18,26)$, and the rest of the studies dealt with the agenda-setting and policy-formulation (7, 17, 20-25, 28-32). 
The quality of some of the papers entered in the study was low for various reasons. Some of these studies did not well explain the methodology of the study, did not mention the source of information, or did not mention the way of choosing and a number of key informants. Quality control of data collection was not mentioned in most studies. Finally, a number of studies incompletely and superficially had used the existing frameworks.

\section{Application of policy analysis frameworks}

Through 17 included studies in the study, the policy analysis triangle framework was used in two studies, the multiple streams framework in 6 studies, the theory of marked equilibrium in 3 studies, and the framework of advocacy coalition in 3 studies and in 1 article all the three last frameworks were used. Analysis of the application of frameworks and models used in studies are separately provided below.

\section{Stage Heuristic Framework}

No study using this framework was found; but in one of the studies about policy analysis triangle framework of Walt and Gilson for analyzing policy process in Ireland, it was used to organize the content of the study. The use of this framework as a descriptive framework for understanding the way of agenda setting, formulation, implementation, and evaluation of policies was useful.

\section{Policy Triangle Framework (PTF)}

Policy Analysis triangle framework was used in two studies. In the Ireland study, about the model application, no guidance is provided. The underlying factors, policy process and actors' and stakeholders' analysis has been well dealt with (27). In the Russia study, parts of the model including the content, context, process, and actors have been well dealt with. Stakeholders' analysis would be more complete. We observe a good example of the application of the model in this study. The authors have not given an explanation of the model and its help in the analysis (19).

\section{Institutional Analysis and Development Framework} (IADF)

This framework was used in only two studies. In the study by Martinez, this framework was used to study the implementation of tobacco control policies in hospitals in Spain. In general, this study was methodologically weak, where the framework was superficially used that seems not to be able to contribute to the research analysis. A model component in this study is not visible too. About the application of the model, no guidance was provided. It seems that the same results could be achieved through no referring to IAD (common barriers to implementing tobacco control policies in hospitals). The way of collecting or analysis of data is not clear (18). In another study, this framework was used to analyze the implementation of smoke-free policy in three communities in the state of Kentucky. The authors of IAD model and its help in the analysis have well stated some explanations that it is a promising model which deals with both policy adoption and its implementation. This study is a good example of the application of this model. But it is noteworthy that in this study, only the variables and some parts of the model were chosen and applied for analyzing smoke-free policies, and it was not applied completely.

\section{Multiple Streams Theory (MST)}

In seven studies this framework was used. Most of the studies were done at the state level and in America. In most studies, model components were not mentioned explicitly. Two studies were performed in the state of Kentucky America. In the first study, the use of this model had contributed to problem perception, but this model was limited to explaining "why" of the model. Methodology of this study was unclear (22). In another study on the model and its application in this study and its limitations, some explanations were given. This model adequately explained that how and why the bill did not become law and the three streams were not joined together (20). In another study in America Tennessee, a component of the model was used implicitly, and the classification of the three streams was not performed explicitly (7). In all three of these studies, it seems that the advocacy coalition framework is a more appropriate framework to be used. In another study in California America, the political stream is not separately mentioned. In this study, the model of Kingdon was criticized and evaluated (31).

In the study in Canada, the model and its help in the analysis were sufficiently dealt with, and this model clearly had shown that how the problem changed and that there is no agreement for the solution of the problem. This study showed the need to link the three streams. This study did not address the question of how the link was made. The study also tended to combine political and policy streams (17).

The study conducted in Turkey is a very good example of the application of Kingdon streams model. In this study, all components of the Kingdon model are discussed well. The authors have also added a fourth stream called the global stream to their model (21).

In the UK study, a guidance was provided for the application of the model. In this study, it is stated that the value of the model and the applied frameworks is different considering the change in the policy used for analysis (28).

\section{Punctuated Equilibrium Theory (PET)}

This framework was used in four studies $(23-25,28)$. Two studies in America, a study in England and a study was conducted in Bhutan. Three studies were conducted by a US researcher (23-25).

In two studies, the tobacco control policy had not followed the punctuated equilibrium pattern $(23,24)$. In these two studies, a different pattern of policy-making was suggested. In one of the two studies, a guidance was provided on the application of the model (24). In this article due to the presence of two strong coalitions, ACF may be a better choice. In another study in Bhutan, the punctuated equilibrium theory could not predict or describe the nature and speed of uninterrupted policy change pertaining antitobacco law. This study was conducted in a non-Western country (23).

In another study in America, nothing was offered about the application of the model. It is also not fully clear if there is lack of depth in the theory or non-using of it on 
this subject is in this paper. Due to the two coalition with strong underlying belief, ACF would be a better choice in this study (25).

In the UK study, tobacco policy was explained well by using this model. In this study, guidance is provided on the model application. This article states that the value of the model and applied frameworks are different due to the change in the policy chosen for the analysis. This article suggests researchers that before attempting to start the analysis and interpretation, they should pay attention to the nature of the policy change (28).

\section{Advocacy Coalition Framework (ACF)}

In four studies this framework was used. In the Japan study, ACF well explained that how tobacco control policies in Japan before and after the advent of the rights of non-smokers were codified. Although the ACF shows that tobacco control development was designed by rival coalitions, it does not explain well that how the coalition forces, succeeded in transforming their political beliefs into governmental measures (32). This model in the study conducted in Canada showed that how the analysis of power balance among the coalitions led to the understanding of the cause of ending the initial fight over returning the previous tax state. Charts based on $\mathrm{ACF}$, showed the analysis in two-time points: when the tax cuts triumph and when the tobacco strategy won later. This study is an excellent example of how external events led to the transfer of the balance of power between coalitions. Charts among important aspects of what happened were quite useful (30). In another study in the same country, Quebec Tobacco Act was explained using the Advocacy coalition framework. This study is an excellent example of best application of Advocacy coalition framework. In this study, all parts of the model are well addressed (29). In the UK study, guidance is provided on the model application (28).

\section{Discussion}

This study seeks to understand more about the processes of tobacco policy so as to help the processes of policy formulation and implementation in the field. All of the total 17 articles included, had at least used one of the five policy analysis frameworks. Studies indicate that the current policy framework can help understand the process of tobacco control policy.

The findings of the study showed that the most used framework in the articles studied, was multiple streams model. Only in a few studies was referred to framework choice and its suitability for that study.

The findings indicated that most of the included studies were conducted in North America i.e. America and Canada. The majority of studies were published in medical and health journals. The majority of studies had dealt with analyzing the national and state policies. Most of the studies were focused on the analysis of agenda-setting stage. The findings show that it is better to use different models to examine in the same study. Each one of these studies have weaknesses and strengths; for example, streams' model is better in explaining the role of political and external factors, but advocacy coalition framework is more convenient in showing coalitions and networks; so there is no single model that offers a comprehensive description and perception of the policy processes so as each one responds the questions somewhat differently (33). That is why addressing policy through different lenses would be useful. On the other hand, a specific model consists of elements from other models.

As it was mentioned above, most of the models' applications are conducted in Western countries; and some of them that are conducted in non-Western countries like Bhutan (23), seem not to be successful in the validity and applicability test. So we need to expand the applications of these models in other countries and in accordance with their situation and demands, add new parts to it and complement it so as to be able to explain these phenomena. An example of this is a study in Turkey. In the study in Turkey, a fourth stream called the global stream was added to the Kingdon model, because the multiple streams framework was originally developed to understand the internal policy in the US and the role of local actors (21).

As the results of this study showed, we observe a low, incomplete or improper use of models and analytical frameworks of policy in the field of tobacco. In the present study, few studies had used advocacy coalition framework. From the three agenda setting frameworks and theories (MSF, PEF, ACF), the ACF framework is the most detailed framework in terms of elements and factors affecting the dynamics of political sub-system (and hence, political changes). ACF is useful where two or more coalitions are competing on the same subject so as to prioritize their positions in terms of policy. These coalitions are often based on core beliefs strikingly different (11). However, despite the apparent relationship, the advocacy coalition framework and tobacco control policy, few studies have systematically used these frameworks to explain or analyze adopting tobacco control policies. Also as the result of this study showed, in a number of studies with advocacy coalitions in sub-systems, it was better to use ACF in place of other models.

This study has limitations. Among them was this that we only included the articles from five models and other models are not considered. It is offered that in future studies, a wider range of models and frameworks of the policy process be used.

\section{Conclusion}

The present systematical review examined the application of theories and frameworks of the policy process in studying tobacco control policies. This study showed that a number of theories and frameworks are applied, but their application in studies has been limited. Even when political science theories were applied to understand tobacco control policy-making processes, these studies still had significant methodology weaknesses. This study shows the complexity of decision making, and policy-making in the field of tobacco control so recommends that more precise experimental studies are done in the future and numerous theoretical frameworks are used to better guide the policy makers about the process of the tobacco control policies. 


\section{Acknowledgment}

This article was part of a Ph.D. thesis in Health policy by Jalal Arabloo at Tehran University of Medical Sciences (TUMS), grant number "8921557003.". We would like to thank Tehran University of Medical Sciences for the financial support of this study.

\section{Conflict of Interests}

The authors declare that they have no competing interests.

\section{References}

1. Organization WH. WHO report on the global tobacco epidemic, 2008: the MPOWER package. Geneva: World Health Organization 2008.

2. Wipfli H, Samet JM. One hundred years in the making: the global tobacco epidemic. Ann Rev Pub Health.2016;37:149-66.

3. Bump JB, Reich MR. Political economy analysis for tobacco control in low-and middle-income countries. Health Policy Plan. 2013;28(2):123-33.

4. Tomson T, Akkhavong K, Gilljam H. Stakeholders' opinions about a tobacco policy in Lao PDR. Tob Induc Dis. 2009;5(1):1.

5. Chantornvong S, Collin J, Dodgson R, Lee K, McCargo D, Seddon D, et al. Political economy of tobacco control in low-income and middleincome countries: lessons from Thailand and Zimbabwe. Global Analysis Project Team. Bull World Health Organ. 2000;78(7):913.

6. Embrett MG, Randall G. Social determinants of health and health equity policy research: exploring the use, misuse, and nonuse of policy analysis theory. Soc Sci Med. 2014;108:147-55.

7. Mamudu HM, Dadkar S, Veeranki SP, He Y, Barnes R, Glantz SA. Multiple streams approach to tobacco control policymaking in a tobacco-growing state. J Community Health. 2014;39(4):633-45.

8. Clarke B, Swinburn B, Sacks G. The application of theories of the policy process to obesity prevention: a systematic review and metasynthesis. BMC Public Health. 2016;16(1):1084.

9. Ritter A, Bammer G. Models of policy-making and their relevance for drug research. Drug Alcohol Rev. 2010;29(4):352-7.

10.Cullerton K, Donnet T, Lee A, Gallegos D. Using political science to progress public health nutrition: a systematic review. Public Health Nutr. 2015:1-9.

11. Moloughney B. The Use of Policy Frameworks to Understand Public Health-Related Public Policy Processes: A Literature Review. Peel Public Health: Peel Public Health, 2012.

12. Breton E, De Leeuw E. Theories of the policy process in health promotion research: a review. Health Promot In. 2011;26(1):82-90.

13. Sabatier PA, Weible C. Theories of the policy process: Westview Press; 2014.

14. Walt G, Shiffman J, Schneider H, Murray SF, Brugha R, Gilson L. 'Doing'health policy analysis: methodological and conceptual reflections and challenges. Health Policy Plan. 2008;23(5):308-17.

15. Walsh D, Downe S. Meta-synthesis method for qualitative research: a literature review. J Adv Nurs. 2005;50(2):204-11.

16. Moher D, Shamseer L, Clarke M, Ghersi D, Liberati A, Petticrew M, et al. Preferred reporting items for systematic review and metaanalysis protocols (PRISMA-P) 2015 statement. Syst Rev. 2015;4(1):1.

17. Schwartz R, Johnson T. Problems, policies and politics: A comparative case study of contraband tobacco from the 1990s to the present in the Canadian context. J Public Health Policy. 2010;31(3):342-54.

18. Martinez C. Barriers and challenges of implementing tobacco control policies in hospitals: applying the institutional analysis and development framework to the Catalan Network of Smoke-Free Hospitals. Policy Polit Nurs Pract. 2009;10(3):224-32.

19. Lunze K, Migliorini L. Tobacco control in the Russian Federation-a policy analysis. BMC public health. 2013;13(1):1.

20. Kehler S, Hahn EJ. A Policy Analysis of Smoke-Free Legislation in Kentucky. Policy Polit Nurs Pract. 2016:1527154416651406.

21. Hoe C, Rodriguez DC, Üzümcüoğlu Y, Hyder AA. "Quitting like a Turk:" How political priority developed for tobacco control in Turkey. Soc Sci Med. 2016;165:36-45.

22. Greathouse LW, Hahn EJ, Okoli CT, Warnick TA, Riker CA. Passing a smoke-free law in a pro-tobacco culture: a multiple streams approach. Policy Polit Nurs Pract. 2005;6(3):211-20

23. Givel M. Nonpunctuated and Sweeping Policy Change: Bhutan Tobacco Policy Making from 1991 to 2009. Rev Policy Res. 2012;29(5):645-60.

24. Givel M. Assessing material and symbolic variations in punctuated equilibrium and public policy output patterns. Rev Policy Res. 2008;25(6):547-61.

25. Givel M. Punctuated equilibrium in limbo: The tobacco lobby and US state policymaking from 1990 to 2003. Policy Stud J. 2006;34(3):405-18.

26. Fallin A, Goodin A, Rayens MK, Morris S, Hahn EJ. Smoke-free policy implementation: Theoretical and practical considerations. Policy Polit Nurs Pract. 2014;15(3-4):81-92.

27. Currie LM, Clancy L. The road to smoke-free legislation in Ireland. Addiction. 2011;106(1):15-24

28. Cairney P. A 'Multiple Lenses' Approach to Policy Change: The Case of Tobacco Policy in the UK. British Politics. 2007;2(1):45-68.

29. Breton E, Richard L, Gagnon F, Jacques M, Bergeron P. Health promotion research and practice require sound policy analysis models: the case of Quebec's Tobacco Act. Soc Sci Med. 2008;67(11):1679-89.

30.Breton E, Richard L, Gagnon F, Jacques M, Bergeron P. Fighting a tobacco-tax rollback: a political analysis of the 1994 cigarette contraband crisis in Canada. J Public Health Policy. 2006;27(1):77-99.

31. Blackman VS. Putting policy theory to work: tobacco control in California. Policy Polit Nurs Pract. 2005;6(2):148-55.

32. Sato H. The advocacy coalition framework and the policy process analysis: The case of smoking control in Japan. Policy Stud J. 1999;27(1):28-44.

33. Exworthy M. Policy to tackle the social determinants of health: using conceptual models to understand the policy process. Health Policy Plan. 2008;23(5):318-27. 
Appendix: In this study, four search strategies were used: Last Search:2016/12/19

\begin{tabular}{lll} 
Appendix 1. Ovid MEDLINE search strategy 1946 to 19 December 2016 & Items found \\
\hline Search & Query & 260614 \\
1 & (tobacco or smok\$ or cigarette or pipe or cigar or hookah).mp. & 86 \\
2 & ("multiple streams" or kingdon).mp. & 86 \\
3 & "punctuated equilibrium".mp. & 2 \\
4 & "Institutional Analysis and Development Framework".mp. & 247 \\
5 & ("policy triangle" or walt or gilson).mp. & 43 \\
6 & "advocacy coalition\$".mp. & 1 \\
7 & "Stages heuristic".mp. & 729 \\
8 & "Policy analysis".mp. & 1182 \\
9 & 2 or 3 or 4 or 5 or 6 or 7 or 8 & 29 \\
10 & 1 and 9 & \\
\hline
\end{tabular}

\begin{tabular}{|c|c|c|}
\hline earch & Query & Items found \\
\hline 1 & TITLE-ABS-KEY(tobacco or Smok* or cigarette or cigar or hookah or pipe) & 664,300 \\
\hline 2 & TITLE-ABS-KEY("multiple streams" OR kingdon) & 1,258 \\
\hline 3 & TITLE-ABS-KEY("punctuated equilibrium") & 793 \\
\hline 4 & TITLE-ABS-KEY("Institutional Analysis and Development Framework") & 54 \\
\hline 5 & TITLE-ABS-KEY("policy triangle" OR walt OR gilson) & 1,571 \\
\hline 6 & TITLE-ABS-KEY("advocacy coalition*") & 360 \\
\hline 7 & TITLE-ABS-KEY ("Stages heuristic") & 258 \\
\hline 8 & TITLE-ABS-KEY ("Policy analysis") & 10,308 \\
\hline 9 & $\begin{array}{l}\text { ( TITLE-ABS-KEY ( "multiple streams" OR kingdon )) OR ( TITLE-ABS-KEY ( "punctu- } \\
\text { ated equilibrium" ) ) OR ( TITLE-ABS-KEY ( "Institutional Analysis and Development } \\
\text { Framework" )) OR ( TITLE-ABS-KEY ( "policy triangle" OR walt OR gilson ) ) OR ( } \\
\text { TITLE-ABS-KEY ( "advocacy coalition*" ) ) OR ( TITLE-ABS-KEY ( "Stages heuristic" )) } \\
\text { OR ( TITLE-ABS-KEY ( "Policy analysis") ) }\end{array}$ & 14,464 \\
\hline 10 & $\begin{array}{l}\text { ( ( TITLE-ABS-KEY ( "multiple streams" OR kingdon )) OR ( TITLE-ABS-KEY ( "punc- } \\
\text { tuated equilibrium" ) ) OR ( TITLE-ABS-KEY ( "Institutional Analysis and Development } \\
\text { Framework" ) ) OR ( TITLE-ABS-KEY ( "policy triangle" OR walt OR gilson ) ) OR ( } \\
\text { TITLE-ABS-KEY ( "advocacy coalition*" )) OR ( TITLE-ABS-KEY ( "Stages heuristic" )) } \\
\text { OR ( TITLE-ABS-KEY ( "Policy analysis" ) ) ) AND ( TITLE-ABS-KEY ( tobacco OR } \\
\text { smok* OR cigarette OR cigar OR hookah OR pipe ) ) }\end{array}$ & 149 \\
\hline
\end{tabular}

\begin{tabular}{|c|c|c|}
\hline Search & Query & Items found \\
\hline$\# 10$ & (\#9 and \#1) & 162 \\
\hline \#9 & $(\# 2$ or $\# 3$ or $\# 4$ or $\# 5$ or $\# 6$ or $\# 7$ or $\# 8$ ) & 6325 \\
\hline \#8 & "Policy analysis" & 2110 \\
\hline \#7 & "Stages heuristic" & 3 \\
\hline \#6 & "advocacy coalition*" & 40 \\
\hline \#5 & ("policy triangle" OR walt OR gilson) & 3550 \\
\hline \#4 & ("Institutional Analysis and Development Framework") & 5 \\
\hline \#3 & "punctuated equilibrium" & 129 \\
\hline \#2 & ("multiple streams" OR kingdon) & 537 \\
\hline$\# 1$ & (tobacco or Smok* or cigarette or cigar or hookah or pipe) & 320776 \\
\hline \multicolumn{3}{|c|}{ Appendix 4. Cochrane Library search strategy } \\
\hline Search & Query & Items found \\
\hline \#1 & tobacco & 4518 \\
\hline \#2 & mesh descriptor tobacco explode all trees & 124 \\
\hline \#3 & $\# 1$ or \#2 & 4633 \\
\hline \#4 & "multiple near/1 streams" & 0 \\
\hline \#5 & kingdon & 118 \\
\hline \#6 & $\# 4$ or \#5 & 118 \\
\hline \#7 & "punctuated near/1 equilibrium" & 0 \\
\hline \#8 & "Institutional Analysis and Development Framework" & 0 \\
\hline \#9 & "policy near/1 triangle" & 0 \\
\hline \#10 & walt & 144 \\
\hline \#11 & gilson & 117 \\
\hline \#12 & $\# 9$ or \#10 or \#11 & 261 \\
\hline$\# 13$ & advocacy near/ 1 coalition & 0 \\
\hline \#14 & "Stages near/1 heuristic" & 0 \\
\hline$\# 15$ & "Policy analysis" & 52 \\
\hline \#16 & $\# 6$ or $\# 7$ or $\# 8$ or $\# 9$ or $\# 12$ or $\# 13$ or $\# 14$ or $\# 15$ & 429 \\
\hline \#17 & \#3 and \#16 & 4 \\
\hline
\end{tabular}

